Ann. Génét. Sél. anim., г973, 5 (I), го9-123.

\title{
SELECTION IN TWO ENVIRONMENTS IN RELATION TO PLATEAUING IN EGg PRODUCTION ( $\left.{ }^{1}\right)$
}

\author{
M. VAN ALBADA and M. P. F. C. A. TIMMERMANS \\ Department of Poultry Husbandry \\ Agric. University \\ Wageningen (The Netherlands)
}

\section{SUMMARY}

In Random Sample Tests of Putten and Ploufragan plateauing on a low level is observed in a trait with low heritability i. e. mortality, where selection is directed for low levels and an absolute border is present at o p. roo. No plateauing is till now observed in a trait with high heritability i. e. egg weight. In a trait with medium heritability, i. e. p. Ioo lay plateauing has occurred for different periods but was broken through some times.

A selection experiment in two environments, one variable, the other constant showed quite different responses according to trait and environment. Loss of heterosis by mating crossbreds was much more pronounced in a variable environment than in a constant environment. It would be largely recovered by one generation of selection in one sex only. Selection responses for different traits are discussed.

\section{INTRODUCTION}

Poultry breeders will rarely be content with their achievements in improving egg production by breeding and crossbreeding in poultry. Especially when they look at the rapid advances made in breeding for meat production during the last two decades, they may become disappointed in comparing the slow progress - if any obtained by dogged perseverance in their own branch.

This lack of progress under continued selection termed " plateauing "-needs our attention.

(1) Cet article a été présenté lors de la réunion du groupe de travail no 3 (génétique et testage) de la Fédération des Branches européennes de la W. P. S. A., Nouzilly, 7-8 septembre I97I. 


\section{Occurrence of plateauing}

Before discussing the possible causes of plateauing and the means to avoid these dead ends, it is worth while to investigate to what extent plateauing is really occurring. For this reason data were collected of two Random Sample Tests, viz. the R.S.T. at Putten during the periods I956-57 through I96I-62 and I963-64 through r969-70 and those of the R.S.T. at Ploufragan, Côtes-du-Nord, during the latter period. Eigg production data of the year I962-63 in Putten have nct been published because of a fully abnormal production. Progress achieved in three different traits with probably three different levels of heritability will be discussed.

\section{Progress in a trait with supposed high heritability. Egg weight}

In both $R$. S. T. stations a steady increase in egg weight was found. Over the period I956-70 in Putten a highly significant $(\mathrm{P}<0 . \mathrm{oI})$ correlation between time (in years) and mean egg weight was found $(r=+0.846)$. The regression equation $\mathrm{W}=57.93+0.24 \mathrm{I} \mathrm{A}$ shows an annual increase in mean egg weight of a little bit less than one quarter of a gram. Looking at the period of I963-70 similar correlations are found both for Putten ( $+0.876, \mathrm{P}<0.0 \mathrm{I})$ and Côtes-du-Nord ( 0.826 , $\mathrm{P}<0.05)$. The regression coefficients of +0.464 and +0.407 respectively are even higher, indicating that not the slightest sign of plateauing is present.

This means that a steady progress in egg weight has been obtained during the last 5 years, either by improving existing strains and crossbreds or by developing new strains and combinations.

The range between the best (max.) and the worst (min.) entry seems to be fairly constant, showing no signs of losses in between entry variance. That the level of egg weight in the Ploufragan test is a little bit lower than in Putten, may have many reasons, like there are different environment, different entries, different numbers of eggs weighed, shorter testing period in Ploufragan. Summarizing we could state that there are no signs whatsoever for plateauing in egg weight and that eventually when plateauing might occur before long, this might rather be the result of relaxed selection because an optimum has been reached, than of lack of genetic variability.

\section{Progress in a trait with low heritability. Mortality}

Progress in p. Ioo losses per Ioo days of the production period has been studied. Expression of p. Ioo losses per Ioo days has been chosen to reduce the effect of different lengths of testing periods from year to year or between tests. When plateauing might occur in mortality, different causes might be considered :

a) because selection is directed towards low mortality (plateauing on a high level needs not to be considered), there is a natural minimum border of p. Ioo losses, which can not be surpassed.

b) because of a long history of natural and artificial selection for low mortality, the additive portion of heritability will be largely exhausted, causing low heritability and low selection response. As a matter of fact the remaining additive genetic variance will be the calculated regression of effects of genes with non additive gene 
action rather than a minor residue of purely additive gene effects. The remaining non additive genetic variance should mainly be based on genes showing dominance, overdominance or epistasy for high livability. When frequency of these genes becomes high, the detection of heterozygotes becomes difficult because the majority of recessive genes is carried by heterozygotes. This will inevitably lead to plateauing on a low level of mortality.

c) when genetically mortality has reached a minimum level, that even theoretically might be zero, there will still be losses by environmental factors, like diseases and accidents against which no genetic barrier can be present. This will lead towards a phenotypic variability with a skew distribution towards the minimum of zero, which will be responsible for plateauing of mortality on a low level. Definite signs of plateauing were found, though still a rather wide range is present between the best and the worst entry. The minimum mortality is plateauing on a level of about I p. Ioo losses per Ioo days, though occasionally the border of $\mathrm{p}$. Ioo has been reached, which in this case means that no losses have occurred in one entry during the full 344 days of the test.

The Putten test shows a nearly significant decrease in average losses during the full period of 1956 through I970, with $r=-0.476$ (0.I0 $<\mathrm{P}<0.20$ ). The regression equation $\mathrm{L}=4.780-0 . \mathrm{I} 3 \mathrm{I} A$ showing a yearly decrease in mean losses of o.I3I p. Ioo over the last I5 years.

Both Putten and Ploufragan show a steady, though insignificant decrease in average mortality over the period I963 through I970, $(r=-0.3$ I9 and -0.464 respectively), with regression coefficients of - 0.I94 (Putten) and - 0.126 (Ploufragan). Though the minimum level of mortality is clearly plateauing on a level of p. roo per roo days, the total range of entries is still 5 times the minimum level in both tests, indicating that still a lot of work can be done by some breeders in reducing mortality by selective breeding.

\section{Progress in egg production}

Progress in egg production was expressed as p. Ioo lay. Calculation has been done on a hen-housed basis. Therefore progress in egg production is partly due to progress in livability. Expression as p. Ioo lay has been chosen in order to reduce the effects of variation in registration periods within tests and of differences in testing period between tests. Data of birds housed on litter only have been used.

The period of I956 through I962 in Putten shows a slow decline in mean egg production. This decline would have probably been continued in I962-63, when no data have been published, and further in I963-64. Over the period I956 through I964 the decline is highly significant $(r=-0.922, \mathrm{P}<0.0 \mathrm{I})$, the regression equation $\mathrm{L}=66.46-\mathrm{I} .335 \mathrm{~A}$ indicating that mean egg production has declined about 4 p. Ioo every three years. The causes of this decline are difficult to trace back. The experimental farm being entirely new in 1956 , it is reasonable to suppose that after a few years exogenous conditions have developed, interfering with health conditions in the birds to which some entries were insufficiently resistant. This seems to be confirmed by progress in mortality and the increase in range between 
best and worst entries both in p. IOo losses and p. IOo egg production on a henhoused basis.

In the period I963 through I970 a significant increase in egg production has occurred, both in Putten, where the increase was highly significant $(r=+0.935$, $\mathrm{P}<0.0 \mathrm{r})$ and in Ploufragan, where the progress was less pronounced $(r=+0.787$, $\mathrm{P}<0.05)$ but where the starting point was at an II p. roo higher level. During the last three or four years a striking similarity is present both for highest, mean and lowest levels of entries in the two testfarms. According to the regression formula, $\mathrm{E}=52.99+2.693 \mathrm{~A}$ for Putten and $\mathrm{E}=64.43+0.650 \mathrm{~A}$ for Ploufragan, the yearly progress in hen-housed egg production has been somewhat over $2.5 \mathrm{p}$. Ioo in Putten and slightly over $0.5 \mathrm{p}$. Ioo in Ploufragan. In the two testing stations the ranges between highest and lowest entry seem to have decreased, in Putten from $23.0 \mathrm{p}$. Ioo down to $\mathrm{r} 3 . \mathrm{x}$ p. Ioo and in Ploufragan from $20.5 \mathrm{p}$. Ioo down to I5.o p. Ioo. This decrease in range seems largely to be due to an increase of the lower level, by elimination of insufficient entries. Nevertheless there is an indication of improvement in the higher ranges as well. In Putten for a long period, extending from 1956 through I 965 , the upper limit of entries has been moving between 66.8 and 72.0 p. IOO, without any sign of progress. That might indicate that with those flocks under the prevailing circumstances a plateau in egg production of about $67-72 \mathrm{p}$. Ioo has been reached and that no breeder had managed to break this ceiling in performance. The optimal results obtained at Ploufragan in the years I963-I965 show similar upper limits between 70 and 73 p. roo. Starting in 1965-66 this plateau seems to be raised to a maximum of 78 to 79 p. Ioo, both in Putten and in Ploufragan. This indicates that either by selective breeding or by improvement of environment or by both, the plateau which had been present probably for many years, could be raised rather suddenly. The results of Ploufragan over the last three years show a steady increase in egg production both in the mean and the upper and lower limits, which is quite near to the average increase through the whole period reported. This might indicate that in the Ploufragan results plateauing is not yet occurring. In the Putten results of the last three years however some signs of plateauing seem to be present both in the highest, the lowest and the average level. Taking into account the minimum level of mortality, there is evidence for the supposition that modern layers have reached a plateau of about 80 p. Ioo survivors production. Future experience only can give the answer whether this is a fixed plateau or not.

\section{Possible causes of plateauing}

Many causes for plateauing in a quantitative trait can be suggested. Generally spoken, plateauing will occur under selective breeding when the population is in an equilibrium state which can not be changed by selective breeding or when genotype-environment relations occur which counterbalance genetic improvement by environmental deterioration. The latter case however is not very likely to occur.

A genetic equilibrium which is resistant to selective breeding requires different propositions :

I. In closed flock breeding, the additive part of genotype induced phenotypic variance should be exhausted. This would mean that genes with purely additive action or showing complete or incomplete dominance and favouring the trait selec- 
ted for, will be completely fixed. For genes showing overdominance either a labile equilibrium should be reached by combined selection and breeding, or the genes should be fixed by continued inbreeding. Similar possibilities are present for genes showing epistasy. Instable equilibria of this kind can always be changed, but not always improved, by reduced or increased selection pressure, by outbreeding or by changing the environment.

2. In crossbreeding similar but still more instable situations might occur, when the parent populations are partly selected in closed flock breeding. Reciprocal recurrent selection procedures can lead to highly instable and suboptimal performances in crossbred populations. As will be shown later from results obtained by crossbreeding commercial hybrids, dominance and epistasy may have a preponderant influence on heterosis, which can quickly be fixed by selective breeding in one sex only, though further improvement is much more difficult.

3. As far as environment is concerned, it might well be true that a certain environment is conceiling genetic differences, because phenotypic expression is suppressed by environmental conditions, either because the given environment is prohibitive for phenotypic expression of the genotype or because sources of environmental variation are largely covering up the effects of genetic variation. In the first case either the environment should be radically changed or the selection criterion should be differed ; in the second case, sources of environmental variation should be eliminated.

Plateauing of survivors egg production at a level of $80 \mathrm{p}$. Ioo will indicate that the average interval between successive eggs in a clutch is about 26 hours.

With a lighting scheme of 14 hours of light and Io hours of darkness this will be good for an average clutch length of 4 , giving $80 \mathrm{p}$. Ioo production. In order to increase the average clutch length with I egg up to 5 eggs, the ovulation retardation in relation to time should be decreased from 2 to I, 5 hours, reducing the average ovulation interval from 26 to 25.5 hours. This change in clutch length will increase egg production from $80 \mathrm{p}$. Ioo to $83.3 \mathrm{p}$. Ioo. It has been shown long ago (VAN ALBADA, I955) that selection for clutch length can be a far more effective tool in selection for egg production than selection for egg number itself. Clutch length turned out to be less susceptible to environmental differences than egg number, provided that differences in age, stage of production and lighting pattern do not occur or are largely reduced. From. ducks it is well known that an ovulation interval of 24 hours is good for extremely large clutches and annual egg productions up to 350 eggs for complete breeding flocks. Therefore selection for clutch length is likely to be one of the major tools in overcoming plateauing in egg production.

\section{Effect of environmental variation in selection}

When sources of environmental variation are covering up phenotypic effects of genetic differences, selection effects might be improved by artificially reducing the environmental variation. At the Department of Poultry Husbandry of the Agricultural University of Wageningen an experiment has been started in 1966 for investigation of the occurrence and the importance of genotype-environment 
interactions. This experiment is also suitable for investigation of the effect of reduction of environmental variation on selection response.

Main thought behind the concept of the experiment has been that if environmental and genetic variance are mainly acting additively as mostly is assumed, a radical reduction of environmental variability would result in an increase of both heritability and selection response of quantitative traits. Whenever important interactions between environment and genotype might occur, the elimination of environmental variation might eliminate phenotypic effects of genetic differences between individuals like differences in susceptibility for infections, for fluctuations in daylength, etc. This might lead to reduced selection response and/or environment bound selection effects making the birds less suitable for environments different from the environment they are selected for.

\section{Procedure}

Two polyhybrid populations were produced and divided at random (within maternal half- and full-sibs) over two environments, one "variable ", the other " constant". Selection for a complex production character (estimated total eggshell production) was practised in the two environments seperately, giving rise to two separate lines in each of the two populations, viz. a "constant environment line " and a "variable environment line".

Extensive description of the two environments can be given elsewhere. Here a short description will suffice.

The variable environment was created in a conventional layer house with partly open windows and a naturally ventilated ridge, with natural light only, providing daylength fluctuations between 7.45 and 16.45 hours all over the year. The birds were housed in pens of $4 \times 4 \mathrm{~m}$ on litter, with slatted floors underneath the feeders.

The constant environment was created in an airconditioned battery house at constant temperature $\left(\mathrm{IO}^{\circ} \mathrm{C}\right)$ and humidity $\left(80 \mathrm{p}\right.$. IOO) with $\mathrm{I}_{4}$ hours of light daily at an intensity between 250 and 650 lux. Local differences in light intensity did not show any effect on egg production. Birds were housed in individual cages with $33 \mathrm{~cm}$ frontwidth.

Birds were housed at I8 weeks of age and trapnested daily up to 434 days of age, except for the first year when the birds had been hatched one month later than the following years with hatching from one week in April to one week in May. In that first year trapnesting was stopped at 403 days of age.

\section{Course of the experiment}

\section{6 :}

Hatching eggs were obtained from commercial breeders and set for hatching, giving rise to 4 different hybrids :

a) a dutch three-way cross in the White Leghorn (A)

b) an american hybrid in the White Leghorn (D)

c) an Australorp $\times(R I R \times R I R)$ crossbred from dutch origin (R)

d) an Australor $p \times(R I R \times N H s)$ crossbred from dutch origin $(\mathrm{H})$ 
All the hybrids were based on different registered strains, except for the Australorp where the same strain was used in both hybrids. The chicks were raised on litter up to 18 weeks of age and then divided at random over the two environments and trapnested up to 403 days of age.

1967:

Reciprocal crossbreds were made both in the White Leghorn $(\mathrm{A} \times \mathrm{D}$ and $\mathrm{D} \times \mathrm{A})$ and the heavy breeds $(\mathrm{H} \times \mathrm{R}$ and $\mathrm{R} \times \mathrm{H})$ by random pen matings in the layer house. Chicks hatched were reared in confinement up to 8 weeks of age and in shelters on range from 8 to I8 weeks of age. At I 8 weeks of age the pullets of each reciprocal mating were divided at random over the two environments and trapnested up to 62 weeks of age.

1968:

Pullets housed in the layer house were pen mated at random with randomly chosen males, taking care that all dams were mated with sires of the reciprocal cross $(\mathrm{AD}$ ma'e $\times$ DA female, etc.). For collecting hatching eggs, those females were used of which large settings could be obtained in order to produce large maternal full- and half-sib families (minimum 6 , average about 8 maternal full and half-sibs). So dams used for breeding were selected for (hatching) egg production, but sires were unselected. Each maternal full- and half-sib family was divided at random over the two environments creating the base of the environment-bound lines to be selected. Birds were raised on litter from o to 8 weeks of age and on range from 8 to 18 weeks.

At $\mathrm{r} 8$ weeks females were housed either in the layer house (variable environment) or in the battery house (constant environment) and trapnested up to 62 weeks of age.

1969:

Females hatched I 967 were selected for estimated total egg shell production and used for individual matings with cocks hatched in I 968 from dams selected for part-time eggshell production. The cocks were selected for part-time eggshell production of their maternal full- and half-sibs. Females previously housed in the layer house were used for reproducing the layer house (variable environment) line, females previously housed on cages were used for reproducing the battery (constant environment) line. Similarly the sires were used on basis of maternal sib performance in either the layer house (for the variable environment line) or the battery (for the constant environment line). Chicks hatched were reared on litter from o to 8 weeks and on range from 8 to 8 weeks and then placed in the environment their parents had been selected for. Trapnesting was continued up to 62 weeks of age.

1970 :

A similar selection procedure was followed as in the preceding year and matings were performed similarly. Chicks were reared in the same way as previous years. Pullets from each full sib family of each of the four selected strains were divided at random over the two environments in order to check birds selected in one environment for performance in both the innate and the foreign environment. In every year egg production was recorded 7 days a week. 


\section{Estimation of total shell production}

Eggs were weighed individually 3 times with 3 months intervals, 3 eggs in succession. Each time one of the 3 eggs weighed was broken, the shell rinsed with water and weighed in air-dry condition. The average weight of the 3 shells was multiplied with total egg number for calculation of the estimated total shell production. Moreover total and mean egg weight for each group was estimated one day every fortnight. The results of these egg weight data were used in this paper. For birds hatched I966 however, because of shortage of labour and equipment, eggs could be weighed only once when the birds were about 9 months old. Therefore egg weights of birds hatched I 966 are not strictly comparable with those of the later years.

\section{Preliminary results}

Because many of the data collected have yet to be punched, a complete analysis of data comprising tests of significance has still to be made. Moreover some data have not been calculated in the proper way. For instance data obtained by multiplying, like total egg production in $\mathrm{kg}$. per group have been obtained

(a)

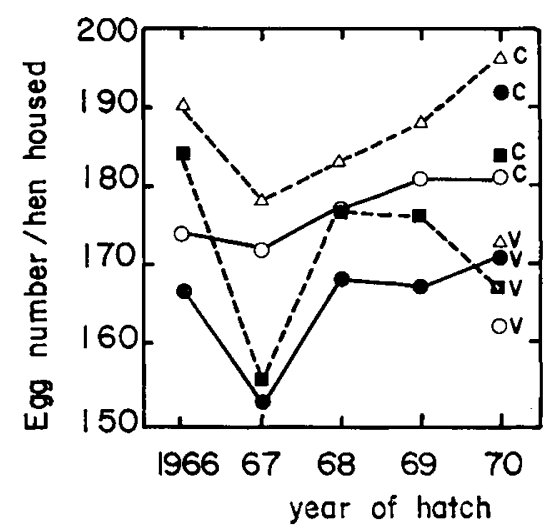

(b)

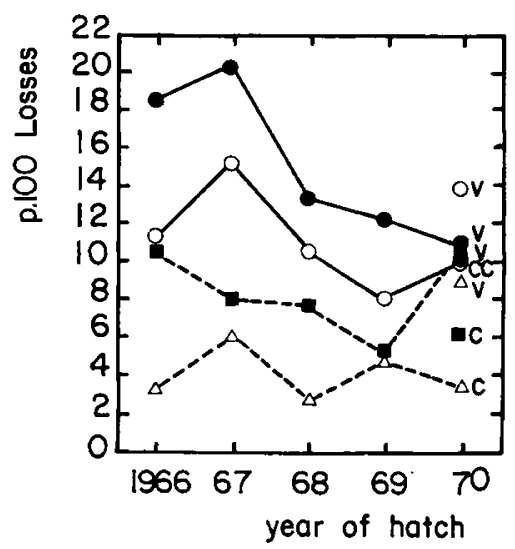

FIG. I. - Selection in two environments

Sélection dans deux environnements

a. Egg number/hen housed

Nombre d'cufs/nombre de poules mises en poulailler

b. p. roo Losses

p. 100 pertes

\section{Legend for figures 1 à 5}

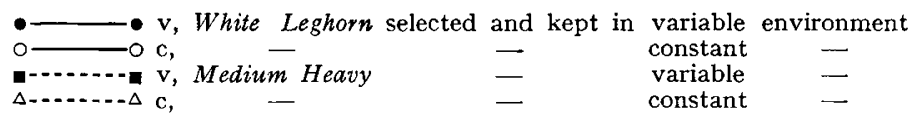

Loose points in 1970 :

- c, $W L$ selected in variable, kept in constant environment

$\circ \mathrm{v}, W L$ - constant, - variable

$\begin{array}{llllll}\text { a c, } M H & - & \begin{array}{c}\text { constant, } \\ \text { variable, } \\ \text { v, } M H\end{array}- & - & \begin{array}{c}\text { variable } \\ \text { constant } \\ \text { variable }\end{array}\end{array}$ 
by multiplying the averages (mean egg number $\times$ mean egg weight) instead of multiplying individual data and calculating the mean product afterwards. Egg number of birds hatched I966 has been corrected for length of period. This however will neither affect the trends in the results or the sign of the differences. Therefore the preliminary results will be presented in the form of graphs without giving the exact figures to the last decimal.

Progress in egg number per hen-housed is shown in fig. I $a$.

Crossbreeding two randomly chosen commercial hybrids, previously bred for combining ability is likely to result in a loss of heterosis in reproductive traits (egg production and livability). A decline in hen-housed egg production is observed in both breeds and in both environments, though much more pronouced in the variable environment in both hybrids. This indicates that heterosis as well as loss of heterosis may be much more pronounced in a variable environment than in a well protected constant environment. Loss of heterosis seems to be more pronounced in the Medium Heavy breed cross than in the White Leghorn probably because of the use of the same sire strain in the two hybrids of the Medium Heavy breed. Selection for egg production in females only has resulted in a complete recovery in the White Leghorn of the losses in the previous year in both environments and a recovery of the major part of loss in egg production in the Medium Heavy breed. This might indicate that the heterosis in the original crossbreds has been largely due to a small number of highly effective autosomal dominant or epistatic genes, easily recovered by selection in the females only.

In the variable environment continued selection for total egg shell production in two following years in both sexes has been completely unsuccessfull in the Medium Heavy breed and hardly better in the White Leghorn. The negative result in the Medium Heavy breed in the last year is largely due to an increased mortality as can be seen from fig. I $b$. In the constant environment a positive response is present, which is more pronounced in the Medium Heavy breed than in the White Leghorn. In both breeds egg production in the variable environment in the last year exceeded slightly the level of the initial commercial hybrids. This may be largely due to environmental circumstances, since the initial hybrids were raised in confinement, whereas later generations have been raised on range from 8 to 18 weeks. When kept in the constant environment the lines selected in variable environment show much better results (compare $v$ with $\bullet c$ and $+v$ with $+c$ ) ; in the White Leghorn these even exceed the original hybrids.

Progress in p. Ioo losses from diseases and mortality are shown in fig. I $b$. Losses are lower in the Medium Heavy breeds than in the White Leghorn and also lower in the constant environment than in the variable environment. In the constant environment the increase in losses which had occurred in the second generation in both breeds has been restored, but after two generations of selection mortality is still at the same level as in the initial hybrids. In the variable environment there has been a substantial improvement in the White Leghorn where mortality was originally very high, but after a continued decrease in the Medium Heavy breed mortality in the last year returned to the original level.

Progress in body weight at 18 weeks of age is presented in fig. 2 a. Since all birds are kept under the same conditions up to I 8 weeks of age, no environmental differences are to be expected except foe effects working through selection 
in the laying period. No important directional changes in body weight at I8 weeks seem to have occurred.

Progress in body weight at 62 weeks of age is presented in fig. $2 b$. Except from a tendency for increased body weight in the Medium Heavy breed in the last year, no clear directional changes in body weight have occurred.

The same holds true for gain in weight from 18 to 62 weeks of age, presented in fig. $3 a$.

(a)

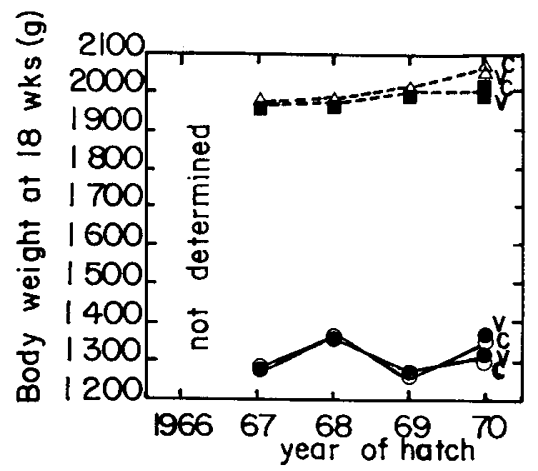

(b)

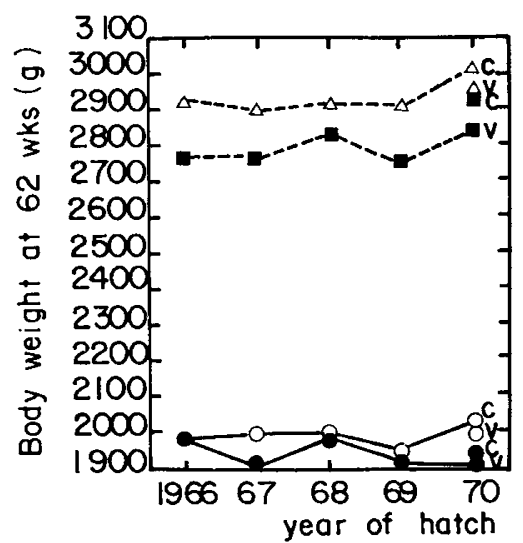

FIG. 2. - Selection in two environments

Sélection dans deux environnements

a. Body weight at $\mathrm{I} 8 \mathrm{wks}$ (g)

Poids corporel à 18 semaines (g) $b$. Body weight at 62 wks (g)

Poids corporel à 62 semaines (g)

Progress in mean egg weight is shown in fig. $3 b$. Though heterosis is not expected to be of much importance in egg weight, crossbreeding the commercial hybrids together with suspension of selection results in a severe drop in egg weight in the White Leghorn. After that in the constant environment no important further change in egg weight has occurred, but in the variable environment the decline has continued during the two last generations, notwithstanding the selection for total shell weight. Comparison of results of the same population in variable and constant environment in all cases shows that the environment in itself does not have much influence on egg weight. In the White Leghorn egg weight is about I/2 gram higher in the constant environment in both strains ; in the heavy breed no differences of this kind can be found. The heavy breed shows a steady decline in egg weight in the variable environment but no consistent changes in the constant environment.

Progress in mean shell weight is shown in fig. $4 a$. In the variable environment shell weight has decreased in both breeds, except for the last generation where a recovery can be observed. Comparable with the trend shown in egg weight, the decline has been much more severe in the White Leghorn than in the Medium Heavy breed. In the constant environment results are quite different. 
After an initial decrease, though smaller than in the variable environment, the White Leghorn shows some stabilisation followed by an increase in the last generation. In the Medium Heavy breed, where shell weight was initially much

(a)

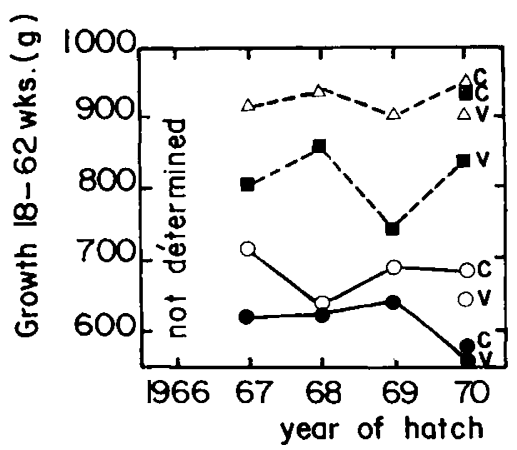

(b)

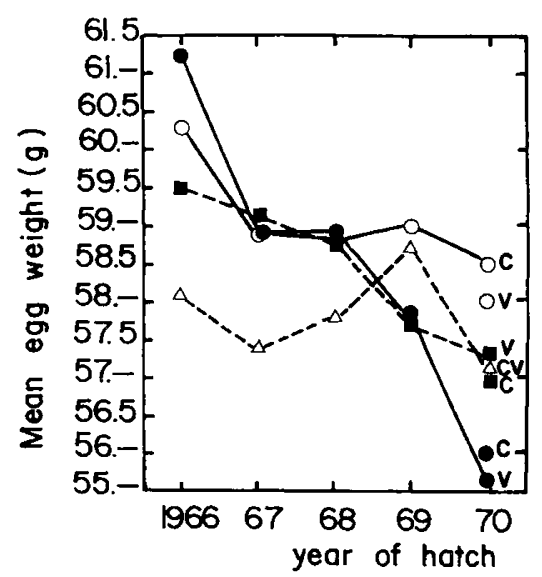

FIG. 3. - Selection in two environments

Sélection dans deux environnements
a. Growth $18-62$ wks (g)
Croissance de 18 à 62 semaines (g)
b. Mean egg weight (g)
Poids moyen des aufs (g)

lower in the constant environment, during selecting a steady increase has occurred. Altogether changes in egg weight and shell weight seem to be rather different and difficult to explain.

Progress in shell quality as expressed as p. Ioo shell is presented in fig. $4 \mathrm{~b}$.

(a)

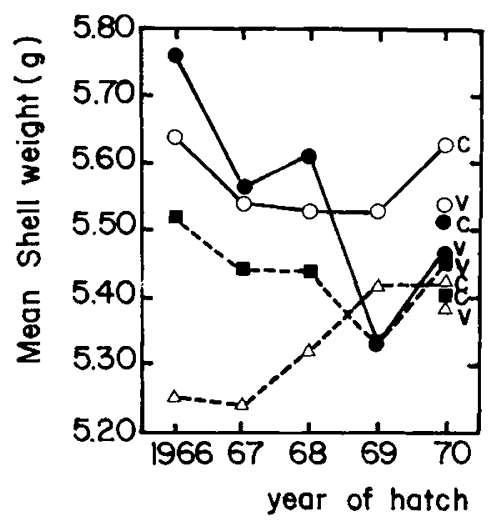

(b)

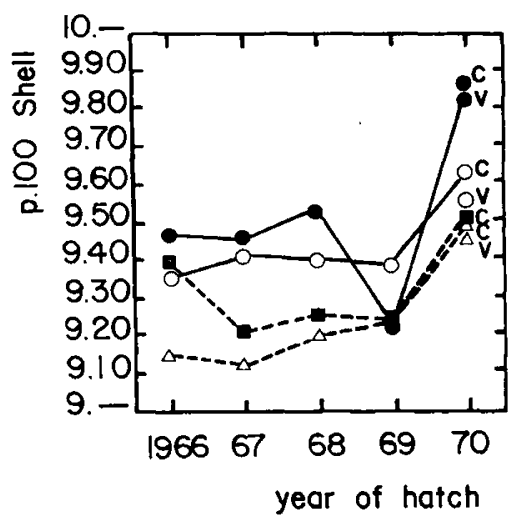

FIG. 4. - Selection in two environments

Sélection dans deux environnements

a. Mean shell weight (g)

Poids moyen des coquilles ( $\mathrm{g}$ ) b. Shell p. Ioo

p. 100 de coquille 
Except for some irregularity in the White Leghorn-strain in the variable environment, there has been a stabilisation of shell p. Ioo with a tendency to increase in the last generation.

Progress in total shell weight produced, being the character selected for, starting with I969, is presented in fig. $5 a$. Here differences between environments are even more pronounced than in hen-housed egg production. Again both loss in heterosis and recovery after selection for hatching egg production are much more pronounced in the variable environment than in the constant environment. In the variable environment, selection for total shell production seems to have been completely unsuccessful, showing a slight decline rather than an increase. However when the same strains are transferred to the constant environment, it turns out that the White Leghorn shows a production which exceeds both the production of the original hybrids and of the line selected in constant environment. In the Medium Heavy breed however the effect of transferring the variable environment line to the constant environment, though clearly present, is much smaller and its production in this case still does not match the original hybrid population completely. In the constant environment both breeds show a steady increase in total shell weight, which is more pronounced in the Medium Heavy breed than in the White Leghorn.

However when these lines are transferred to the variable environment (viz. $\Delta v$ and $\bigcirc v$ ), their total shell production is reduced to a similar level as is shown by the lines directly selected in the variable environment.

(a)

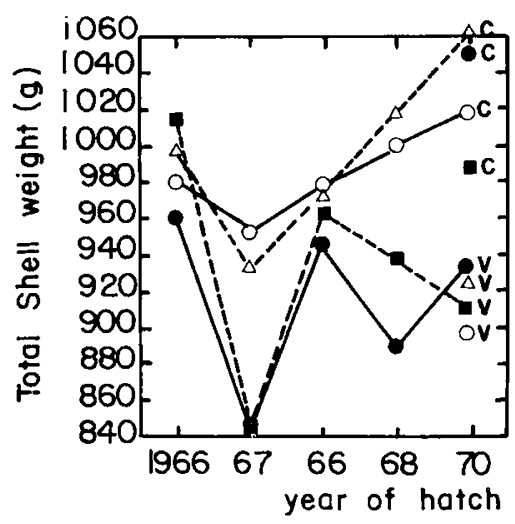

(b)

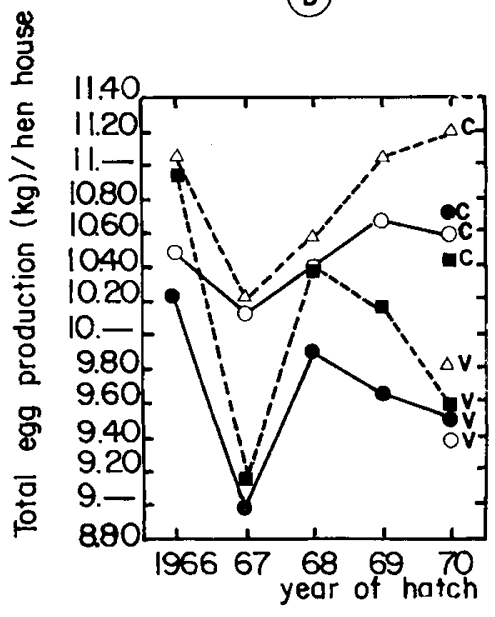

FIG. 5. - Selection in two environments

Sélection dans deux environnements
a. Total shell weight (g)
Poids total des coquilles (g)
b. Total egg production $\mathrm{kg} /$ hen housed Production d'eufs totale en $k g$ par poule mise en poulailler

In fig. $5 b$, progress in total $\mathrm{kg}$ egg production is presented. As might be expected in view of the fact that it is the major component of the trait selected for, the trends are much the same as in total shell weight, though decline in 
total egg production is more pronounced in the variable environment and increase is less pronounced in the constant environment. This is compensated for in total shell production, by increase in shell percentage.

\section{DISCUSSION}

In the variable environnent, crossbreeding two commercial hybrids resulted in a considerable decrease in such traits which are generally considered to show heterosis in crossbreeding. This holds for egg number and for composed traits of which egg number is an important part, like total egg production in $\mathrm{kg}$ and total shell production. It is also visible in livability, expressed as its inverse, p. Ioo losses, but mainly in the White Leghorn. In this case it is likely that the increase in mortality has been alleviated, because in the first year the hybrids have been reared in complete confinement, whereas in following years birds were reared on range from 8 to I 8 weeks, which is apt to improve viability. Also it was observed that one of the original White Leghorn hybrids was highly susceptible for coccidiosis and needed repeated medical treatments. The same hybrid showed much cannibalism and feather picking, which was even extended towards males of the other hybrid placed in the pens. Both failures disappeared largely after crossbreeding with the other White Leghorn hybrid. Therefore mortality in the double crossbred generation of 1967 will have increased less in comparison with the average of the two original crossbreds.

Since the decrease in heterosis observed in the variable environment was considerably alleviated in the constant environment, it is considered that important factors responsible for the expression of heterosis will not show their action in a well protected constant environment. They may therefore be responsible for reaction on environmental factors prevailing in the variable environment, among which can be mentioned :

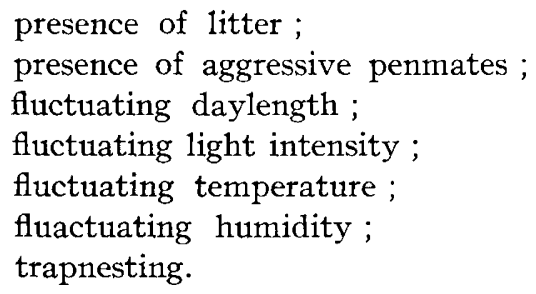

presence of litter;

presence of aggressive penmates ;

fluctuating daylength;

fluctuating light intensity ;

fluctuating temperature;

fluactuating humidity;

trapnesting.

Elimination of all of these factors in he constant environment will have masked the effect of loss of heterosis. Daylength may have been a major factor in this relation, since it was observed that the lag in egg production during shortening daylength was much pronounced in the 1967 generation than in the preceeding and following years. This lag in egg production was much more pronounced in the Medium Heavy breed than in the White Leghorn. As stated before, it can be concluded from the rapid recovery of egg production after one generation of selection in females only, that a small number of dominant or epistatic factors with relatively big effects may be involved in these heterotic phenomena.

Segregation for these non-additive traits might be responsible for the decline 
in total hen-housed egg production and total shell weight (fig. $5 a$ and $5 b$ ) in the variable environment. This segregation will have occurred in the constant environment as well, but there these effects will not be visible because of the protected constant environment.

On the other hand sources of environmental variation in the variable environment may be considered to be responsible for the lack of effect of selection for the additive part of genetic variation. In the constant environment selection has had some effect in these traits. However when the strains selected in the constant environment are transferred to the variable environment, the lack of selection for heterotic traits is revealed and the effect of additive gene effects is disturbed by the high environmental variation and this might explain why egg production is reduced to similar levels as in the groups selected in the variable environment. In the scope of this reasoning it should be expected that the strains selected in the variable environment would lay at a lower rate than the strain selected in the constant environment. This holds true for the Medium Heavy breed, but not for the White Leghorn. So we have still to query that hypothesis.

In view of the problem of plateauing in egg production, it can be stated that signs for plateauing are evident in both breeds in the variable environment, and probably also in the White Leghorn in the constant environment, but not yet in the Medium Heavy breed. Notwithstanding that, it is clear that it has at least been possible in the constant environment to fix the level of production of the original hybrids by pure breeding.

It would be interesting to know what can be achieved by crossbreeding the two newly developed lines of constant and variable environment. A small experiment of this kind with the Medium Heavy breed is in progress in cooperation with the Poultry School at Almelo (1). In the variable environment however, attempts to fix the original level of production of the hybrids by pure breeding have completely failed till now. Unfortunately the strains selected in the constant environment will also fail when transferred to the variable environment.

Selection for a complex character, total egg shell production, which can be considered as the product of three different characters, viz. egg number, egg weight and shell p. Ioo may show different responses in each of the composing traits. Responses have been different according to breeds and environments. In the White Leghorn, egg weight has decreased considerably in the variable environment and far less in the constant environment.

In the Medium Heavy breed a small decrease in the variable environment is seen and no clear trend in the constant environment. Though egg weight is expected to have a higher heritability than egg number, it turns out that variation in egg number still has a larger influence on total egg production in $\mathrm{kg}$ than variation in egg weight. After a certain time the picture might change, as is demonstrated by the progress in shell percentage, which after an initial indifferent period, has started to contribute in progress in total shell production in the last generation.

Much more information will be collected when the complete data will be punched, but still it seemed worth while to present these preliminary results which may stimulate thinking about selection problems.

( $\left.{ }^{1}\right)$ Unfortunately broken of because of disease of the manager. 


\section{RÉSUMÉ}

\section{SÉLECTION DANS DEUX ENVIRONNEMENTS EN RELATION AVEC LE PHÉNOMÈNE DU PLAFONNEMENT POUR LA PONTE}

Dans les tests sur échantillons pris au hasard de Putten et de Ploufragan, le taux de mortalité tend, pour les diverses populations, à se niveler à une faible valeur; il s'agit d'un caractère d'héritabilité peu élevée, où la sélection vise à obtenir la valeur la plus faible possible et où le taux de o p. Ioo constitue une limite absolue. Aucun plafonnement n'est observé jusqu'ici pour un caractère d'héritabilité élevée comme le poids de l'œuf. Pour un caractère d'héritabilité moyenne, le pourcentage de ponte, un plafonnement s'est présenté à différentes périodes mais a été surmonté à plusieurs reprises.

Une expérience de sélection dans deux environnements, l'un variable, l'autre constant, a montré des réponses tout à fait différentes suivant le caractère et le milieu considéré. Une perte d'hétérosis en accouplant des produits de croisements était beaucoup plus prononcée dans un milieu variable que dans un milieu constant. Elle serait largement regagnée par une génération de sélection dans un sexe seulement. Les réponses à la sélection pour divers caractères sont discutées.

\section{REFERENCES}

VAN AlBadA M., I955. On the significance of some characteristics of egg production in breeding utility breeds of poultry. Neth. J. Agric. Sci., 3, 2, I35-154.

Bulletin d'information. Station expérimentale d'Aviculture de Ploufragan, Côtes-du-Nord, I963-197o. JaArverslag. Stichting voor het Fokkerijwezen bij de Pluimveehouderij, Zeist, I957-I970. 